\title{
Effects of Therapeutic Horseback Riding on Cognition and Language in Children With Autism Spectrum Disorder or Intellectual Disability: A Preliminary Study
}

\author{
Sara Kwon, $\mathrm{MD}^{1}$, In Young Sung, $\mathrm{MD}, \mathrm{PhD}^{1}$, Eun Jae Ko, MD, $\mathrm{PhD}^{2}$, Han Seon Kim, $\mathrm{MD}^{3}$
}

\author{
${ }^{1}$ Department of Rehabilitation Medicine, Asan Medical Center, University of Ulsan College of Medicine, Seoul; \\ ${ }^{2}$ Department of Physical Medicine and Rehabilitation, Ulsan University Hospital, University of Ulsan College of Medicine, Ulsan; \\ ${ }^{3}$ Department of Rehabilitation Medicine, Ulsan City E Hospital, Ulsan, Korea
}

Objective To investigate if therapeutic horseback riding (THR) can improve language and cognitive function in children with autism spectrum disorder (ASD) or intellectual disability (ID).

Methods We conducted a prospective case-control study on children diagnosed with ASD or ID. Eighteen and 11 children were enrolled for THR and control groups, respectively. For 8 weeks, those in the THR group underwent conventional therapy plus 30 minutes of THR per week while controls only received conventional therapy. Participants' language (using Receptive and Expressive Vocabulary Test [REVT] and Preschool ReceptiveExpressive Language Scale [PRES]) and cognitive abilities (using Kaufman Assessment Battery for Children [K-ABC] and the cognitive domain of Bayley Scales of Infant Development-II [BSID-II]) were assessed at baseline and at 8 weeks after treatment.

Results There was no baseline difference between the two groups. In the THR group, there were statistically significant improvements in most domains after THR including receptive and expressive language and cognition compared to those before THR. In the control group, however, only receptive vocabulary ability assessed by REVT and cognitive function assessed by BSID-II showed improvements after conventional therapy. However, there were no statistically significant differences in language or cognitive abilities between the two groups at 8 weeks after treatment.

Conclusion These results suggest that THR might improve language and cognitive abilities. Although the mechanisms and pathways involved in such improvements are currently unclear based on our findings, THR might have potential to optimize language and cognitive abilities of children with ASD and ID.

Keywords Therapeutic horseback riding, Autism spectrum disorder, Intellectual disability, Cognition, Language

Department of Rehabilitation Medicine, Asan Medical Center, University of Ulsan College of Medicine, 88 Olympic-ro 43-gil, Songpa-gu, Seoul 05505, Korea. Tel: +82-2-3010-3800, Fax: +82-2-3010-6964, E-mail: iysung@amc.seoul.kr

ORCID: Sara Kwon (http://orcid.org/0000-0002-7088-3393); In Young Sung (http://orcid.org/0000-0001-6545-6744); Eun Jae Ko (http://orcid. org/0000-0001-7198-5407); Han Seon Kim (http://orcid.org/0000-0001-5031-7987).

(c) This is an open-access article distributed under the terms of the Creative Commons Attribution Non-Commercial License (http://creativecommons.org/ licenses/by-nc/4.0) which permits unrestricted noncommercial use, distribution, and reproduction in any medium, provided the original work is properly cited. Copyright ( 2019 by Korean Academy of Rehabilitation Medicine 


\section{INTRODUCTION}

Recently, there has been increasing interest in therapy using horses as part of integrated rehabilitation treatment programs for various disease entities. Such therapy has been associated with significant positive effects. These therapies are referred to by different terms, including 'therapeutic horseback riding (THR), 'hippotherapy', and 'psychoeducational horseback riding' according to therapeutic focuses of each method. The terminology encompassing all of these different terms is 'equine-assisted activities and therapy (EAAT)'. In general, hippotherapy is led by an occupational therapist, a physiotherapist, and a speech therapist using movement of horse to obtain targeted functional outcomes. It tends to focus on posture, balance, and mobility. THR has broader targeted therapeutic focuses, including physical, social, learning, sensory, and psychological goals, like a relationship between the rider and the horse [1-3].

The majority of previous studies related to EAAT have focused on its effects on physical performance. It has been found that EAAT can enhance physical abilities of children with cerebral palsy or spinal cord injury [1-5] and adult patients with stroke or multiple sclerosis [68]. Although effects of EAAT on physical disabilities are well-documented, there is less evidence of its effects on psychobehavioral aspects. It has been reported that EAAT is effective in children with attention deficit hyperactivity disorder (ADHD), especially several domains of social role behavior and quality of life [9]. A study on effects of THR on post-traumatic stress disorder (PTSD) in military veterans has demonstrated that THR can decrease PTSD scores and relieve clinical symptoms such as re-experiencing, avoidance, negative alterations in mood and hyperarousal [10]. Several randomized control studies conducted in children with autism spectrum disorder (ASD) have demonstrated improvements in social interactions, behavior, and attention after THR $[11,12]$. Moreover, it has been shown that equestrian rehabilitation and onotherapy for adults with intellectual disability (ID) can improve their autonomy and social integration [13].

ASD is characterized by impaired capacity for social communication and interaction across multiple contexts as well as by restricted and repetitive patterns of behavior and interest $[14,15]$. ID is characterized by significant impairments in intellectual functioning and two or more adaptive skill areas [16]. As neurodevelopmental disorders, they have common problems such as self-control, social interaction, attention, learning ability, and social communication [17]. In addition to social communication impairments, approximately half of children with ASD also have diminished intellectual capacity $[18,19]$. Impairments of language and cognition in children with these disorders hinder their social interactions and activities of daily living. These impairments can also increase long-term financial and social burdens placed on caregivers of children with ASD and ID [20,21].

Despite growing interest in THR, only a handful of studies have evaluated beneficial effects of this therapy on psychosocial and behavioral aspects in children with neurodevelopmental disorders like ADHD, ASD, and ID. Even fewer studies have addressed its effects on language and cognitive function. Previous research has demonstrated that EAAT can lead to improved social interactions and attention. Based on this, we hypothesized that cognitive function and communication skills of children with neurodevelopmental disorders could be improved after THR. This preliminary study aimed to investigate if THR could improve language skills and cognitive function of children with ASD and ID.

\section{MATERIALS AND METHODS}

\section{Participants}

This study was approved by Asan Medical Center Institutional Review Board (No. 2016-0338). Participants were eligible for inclusion if the following criteria were met: (1) diagnosis of ASD or ID, (2) age between 6 and 13 years, (3) body weight $<35 \mathrm{~kg}$ and height $<150 \mathrm{~cm}$ (taking horse size into consideration), (4) ability to understand simple instructions, (5) appropriate physical development for rehabilitative horseback riding (judged by medical staff), (6) and informed consent from their legal guardian. Exclusion criteria were as follows: (1) other neurological disorders (such as epilepsy), (2) cardiovascular problems (such as uncorrected symptomatic congenital heart defects), (3) orthopedic problems that could limit physical activities (such as fracture, or severe deformity, or contracture of limb), (4) judged by the medical staff to have problems preventing participation, (5) experience of horseback riding at another institution, or (6) participating in other research. 
In this prospective case-control study, we screened patients who visited the outpatient clinic of the Department of Rehabilitation Medicine, Asan Medical Center from November 1, 2015 to May 31, 2016 to identify eligible subjects. Of these, 29 patients were diagnosed with ASD or ID who had age of 6 to 13 years. Nineteen were excluded according to the exclusion criteria. Additional 24 children were recruited from schools for children with disabilities. Of them, three withdrew before the beginning of the study. Thus, a total of 31 eligible participants who met the inclusion criteria were assigned to either the THR group or the control group. The first 19 children enrolled were assigned to the THR group and the latter 12 were assigned to the control group. During the followup period, one participant withdrew from each group. The withdrawal from the THR group occurred due to personal reasons and the withdrawal from the control group was because the subject's irritability prevented baseline evaluations from being carried out (Fig. 1).

\section{Study design and intervention}

In the THR group, 18 subjects participated in THR while maintaining conventional therapy that they had previously been receiving. In the control group, 11 subjects continued conventional therapy only. Thirty-minute THR sessions were conducted once a week for 8 weeks ( 8 sessions). Before beginning the program, we provided a general orientation for participants and their caregivers. These sessions were held in a $20 \mathrm{~m} \times 40 \mathrm{~m}$ indoor riding center of Let's Run Park, Seoul Riding Healing Center located in Gwacheon, Gyeonggi-do, Korea. Five people participated in each THR sessions: a rider, a rehabilitation horseback riding instructor with a national license and more than 5 years of experience (more than half of which were with an international license), a leader, and two side-walkers on both sides of the horse. The leader skillfully controlled the horse during rehabilitation riding sessions to ensure the safety of the entire course. For the rider's safety, side-walkers walked beside the horse on both sides and helped the rider concentrate on the instructor. The leader and side-walkers were trained

Screening

Among the children who visited clinic of PRM

and diagnosed with ASD or ID, we identified

children who met inclusion/exclusion criteria.

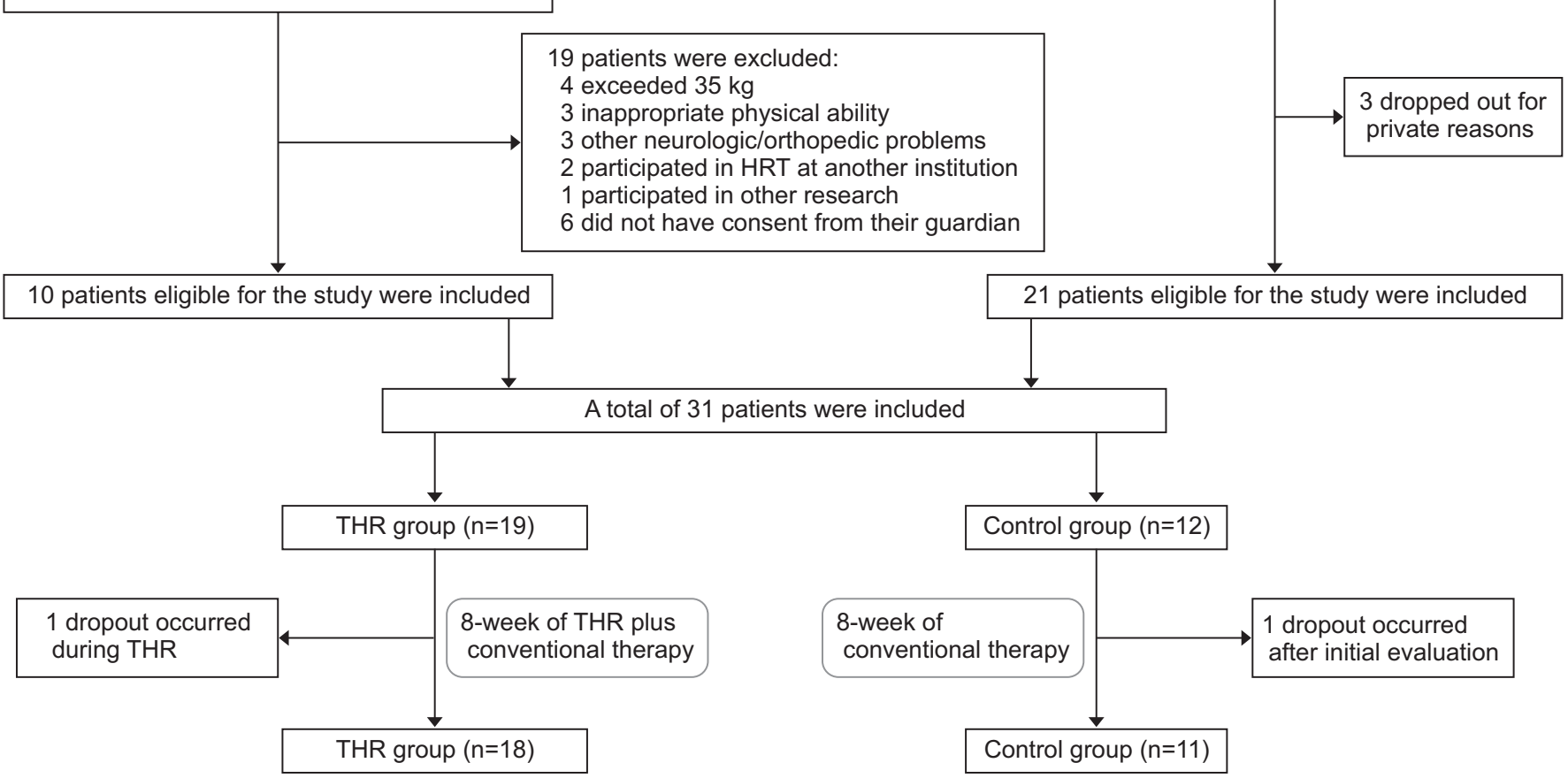

Fig. 1. Flowchart illustrating the inclusion/exclusion criteria and follow-up of subjects in this study. PRM, Department of Rehabilitation Medicine - Pediatric Division; ASD, autism spectrum disorder; ID, intellectual disability; THR, therapeutic horseback riding. 
volunteers. All riders were instructed to wear helmets for safety. Horses used in THR were ponies that weighed about $400 \mathrm{~kg}$ with height (measured from the forelimb to shoulder) of about $150 \mathrm{~cm}$.

Subjects who were assigned to the THR group participated in stretching exercises on the horse for 3 minutes before and after the riding. In particular, THR sessions encouraged participants to interact with horses allowing them to develop a rapport through a variety of activities such as brushing, feeding, and putting stickers on their horses. THR progressed in several steps based on the degree of achievement and the condition of the child. The protocol included learning how to operate reins and how to stop the horse, maintaining appropriate posture, trying more than four transitions (walk-halt-walk) with minimal assistance, and attempting to steer for $50 \%$ of the time with minimal assistance. If children were loud or distracted, their instructors provided feedback immediately. For each session, the instructor and the leader documented the participant's condition, achievements, and shortfalls. These records were shared with the participants' caregivers.

\section{Outcome measures}

Language and cognitive function assessments were conducted to evaluate baseline and post-therapeutic states of participants. We assessed the THR group and the control group at pre- and post-intervention at intervals of 8 weeks.

Language function was evaluated using the Receptive and Expressive Vocabulary Test (REVT) and Preschool Receptive-Expressive Language Scale (PRES). For REVT and PRES, children were evaluated by speech therapists from the Department of Rehabilitation Medicine, OO Hospital. REVT was administered to all subjects. It was developed to assess receptive and expressive vocabulary abilities of young children and adults [22]. The test consisted of two parts: REVT-R (receptive) and REVTE (expressive). REVT-R consisted of 185 items, including 98 nouns, 68 verbs, and 19 adjectives and adverbs. REVT-E also consisted of 185 items, including 106 nouns, 58 verbs, and 21 adjectives and adverbs. REVT-R was performed by selecting one picture corresponding to the target word from four presented pictures. REVT-E allows the subject to look at the presented picture and express the corresponding word. PRES, a tool for assess- ing overall language development and communication, provides language developmental age of the subject being assessed. It was developed to assess receptive and expressive language ability of children aged 2 to 6 years. The test consisted of 45 questions each for expressive and receptive language domains. Contents of PRES included semantics, syntax, and pragmatics. It uses various examination methods, such as pictures, objects, instructions, and interviews [23]. In the present study, PRES was only applied to subjects whose speech and language abilities were deemed to be above the threshold for valid assessment by a speech therapist. Since the vocabulary and the syntax are considered basic parts of communication reflecting language ability $[24,25]$, we used these two testing methods to evaluate language function.

Cognitive function was assessed using the Kaufman Assessment Battery for Children II (K-ABC-II) or the cognitive domain of the Bayley Scales of Infant Development II (BSID-II). These were implemented by experienced pediatric occupational therapists from the Department of Rehabilitation Medicine, Asan Medical Center. K-ABC-II is a standardized test that assesses intelligence and achievement in children aged 3 to 18 years old. Of two theoretical models of intelligence-the Cattell-Horn-Carroll (CHC) model and the Luria model-we used the Luria model in this study. It consisted of four subscales: simultaneous processing, sequential processing, planning, and learning. Scores of the test are calculated as a global score called Mental Processing Index (MPI) based on agestandardized scores and percentile ranks [26]. If the KABC-II assessment was difficult to apply, we instead conducted cognitive assessment using the cognitive domain of BSID-II. BSID-II is an evaluation tool for assessing the developmental status of individual children. It consists of mental, motor, and behavior rating scales. Cognitive domain of BSID-II provides developmental age of mental status. The appropriate age of the BSID-II is between 1 and 42 months. However, it is also applicable to children over 42 months of age with developmental delay if their function is below their normal counterparts $[27,28]$.

\section{Statistical analysis}

Statistical analysis was applied using SPSS version 18 (SPSS Inc., Chicago, IL, USA). The Mann-Whitney test and Fisher exact test were used to compare baseline characteristics and initial functional states of the two groups. 
The Wilcoxon signed-rank test was performed to identify within-group changes between pre- and post-treatment. Mann-Whitney analysis was used to compare changes in THR and control groups pre- and post-treatment and pvalues less than 0.05 were considered statistically significant in all tests.

\section{RESULTS}

\section{Baseline characteristics}

There was no statistically significant difference in baseline language or cognitive function between the two groups (Table 1). Participants' ages ranged from 6 to 11 years. Their mean age was $8.2 \pm 1.7$ years in the THR group and $7.5 \pm 1.1$ years in the control group. There were 19 participants diagnosed with ASD. The remaining 10 participants were diagnosed with ID. REVT was performed for all study subjects. Although PRES was tried on all subjects, 6 patients in the THR group and 3 patients in the control group were unable to perform the test because of their inadequate language skills. In the assessment of cognitive function, 5 subjects of the THR group and 2 subjects of the control group were evaluated using K$\mathrm{ABC}$ while the remaining subjects from each group were evaluated using the cognitive domain of BSID-II.

\section{Pre- and post-treatment measurements}

Following the intervention phase, the THR group showed statistically significant improvements in all aspects of receptive and expressive language assessed by REVT $(\Delta$ Reception $=2.67, \mathrm{p}=0.001 ; \Delta$ Expression $=2.94$, $\mathrm{p}=0.011)$ and PRES $(\Delta$ Reception $=2.33, \mathrm{p}=0.005 ; \Delta \mathrm{Ex}-$ pression $=1.73, p=0.007$ ), as well as cognitive function assessed by the cognitive domain of BSID-II ( $\Delta=3.31$, $\mathrm{p}=0.007)$ and K-ABC $(\Delta=4.60, \mathrm{p}=0.042)$ (Table 2$)$.

After conventional therapy, the control group also showed significant improvements in receptive language function assessed by REVT $(\Delta=1.45, \mathrm{p}=0.027)$ and cognitive function assessed by the cognitive domain of BSID-II $(\Delta=2.33, \mathrm{p}=0.042)$. These improvements were to a lower extent than those in the THR group (Table 2).

When we compared score changes in THR group and control group, there were no statistically significant differences (Table 2). Although between-group comparison did not reveal statistically significant difference, the THR group showed statistically significant post-treatment im-
Table 1. Baseline status of THR and control groups

\begin{tabular}{|c|c|c|c|}
\hline & THR $(n=18)$ & $\begin{array}{c}\text { Control group } \\
(\mathrm{n}=11)\end{array}$ & p-value \\
\hline Age (yr) & $8.2 \pm 1.7$ & $7.5 \pm 1.1$ & $0.317^{\mathrm{a})}$ \\
\hline Gender & & & $0.466^{b)}$ \\
\hline Male & 11 & 5 & \\
\hline Female & 7 & 6 & \\
\hline Diagnosis & & & $1.000^{b)}$ \\
\hline ASD & 12 & 7 & \\
\hline ID & 6 & 4 & \\
\hline \multicolumn{4}{|l|}{ Language } \\
\hline \multicolumn{4}{|l|}{ REVT } \\
\hline Reception & $\begin{array}{c}17.44 \pm 19.97 \\
(n=18)\end{array}$ & $\begin{array}{c}13.82 \pm 18.21 \\
(n=11)\end{array}$ & $0.611^{\mathrm{a})}$ \\
\hline Expression & $\begin{array}{c}14.28 \pm 20.60 \\
(n=18)\end{array}$ & $\begin{array}{c}8.82 \pm 17.59 \\
(n=11)\end{array}$ & $0.674^{\mathrm{a})}$ \\
\hline \multicolumn{4}{|l|}{ PRES } \\
\hline Reception & $\begin{array}{c}21.33 \pm 13.32 \\
\quad(n=12)\end{array}$ & $\begin{array}{c}17.00 \pm 12.20 \\
(n=8)\end{array}$ & $0.473^{\mathrm{a})}$ \\
\hline Expression & $\begin{array}{c}15.58 \pm 13.13 \\
(n=12)\end{array}$ & $\begin{array}{c}10.88 \pm 10.44 \\
(n=8)\end{array}$ & $0.343^{\mathrm{a})}$ \\
\hline \multicolumn{4}{|l|}{ Cognition } \\
\hline $\begin{array}{l}\text { Cognitive } \\
\text { domain of } \\
\text { BSID-II }\end{array}$ & $\begin{array}{c}130.38 \pm 21.87 \\
(n=13)\end{array}$ & $\begin{array}{c}136.00 \pm 19.51 \\
(n=9)\end{array}$ & $0.471^{\mathrm{a})}$ \\
\hline K-ABC & $\begin{array}{c}68.60 \pm 19.41 \\
(n=5)\end{array}$ & $\begin{array}{c}66.00 \pm 31.11 \\
(n=2)\end{array}$ & $0.857^{\mathrm{a})}$ \\
\hline
\end{tabular}

Values are presented as mean \pm standard deviation or number (\%).

THR, therapeutic horseback riding; ASD, autism spectrum disorder; ID, intellectual disability; REVT, Receptive and Expressive Vocabulary Test; PRES, Preschool Receptive-Expressive Language Scale; BSID-II, Bayley Scales of Infant Development-II; K-ABC, Kaufman Assessment Battery for Children.

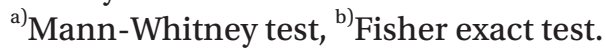

provements in more items than the control group.

\section{Analysis according to diagnosis (ASD vs. ID)}

We also performed data analyses according to diagnosis (ASD or ID). In the ASD group $\left(\mathrm{n}_{\mathrm{THR}}=12, \mathrm{n}_{\text {Control }}=9\right)$, THR was associated with a statistically significant improvement in language function. Subjects with ASD demonstrated improvements in both REVT-R $(\Delta=2.83, \mathrm{p}=0.07)$ and REVT-E $(\Delta=3.25, \mathrm{p}=0.027)$ after THR. Language function evaluated by PRES also improved after THR among 
Table 2. Therapeutic effects of THR and conventional therapy

\begin{tabular}{|c|c|c|c|c|c|c|c|}
\hline \multirow{2}{*}{ Evaluation } & \multicolumn{2}{|c|}{ Baseline } & \multicolumn{2}{|c|}{8 weeks } & \multicolumn{2}{|c|}{$\Delta$ Post-Pre } & \multirow{2}{*}{ p-value ${ }^{c)}$} \\
\hline & THR & Control & THR & Control & THR & Control & \\
\hline \multicolumn{8}{|l|}{ Language } \\
\hline \multicolumn{8}{|l|}{ REVT } \\
\hline Reception & $17.44 \pm 19.97$ & $13.82 \pm 18.21$ & $20.11 \pm 20.84^{\mathrm{a})}$ & $15.27 \pm 18.12^{\mathrm{b})}$ & $2.67 \pm 2.35$ & $1.45 \pm 1.81$ & 0.188 \\
\hline Expression & $14.28 \pm 20.60$ & $8.82 \pm 17.59$ & $17.22 \pm 24.95^{\mathrm{b})}$ & $9.64 \pm 17.62$ & $2.94 \pm 5.03$ & $0.82 \pm 2.44$ & 0.238 \\
\hline \multicolumn{8}{|l|}{ PRES } \\
\hline Reception & $21.33 \pm 13.32$ & $17.00 \pm 12.20$ & $23.67 \pm 13.89^{\text {a) }}$ & $17.88 \pm 12.41$ & $2.33 \pm 1.83$ & $0.87 \pm 1.46$ & 0.069 \\
\hline Expression & $15.58 \pm 13.13$ & $10.88 \pm 10.44$ & $17.17 \pm 14.10^{\mathrm{a})}$ & $11.75 \pm 10.08$ & $1.58 \pm 1.31$ & $0.88 \pm 1.46$ & 0.208 \\
\hline \multicolumn{8}{|l|}{ Cognition } \\
\hline $\begin{array}{l}\text { Cognitive domain } \\
\text { of BSID-II }\end{array}$ & $130.38 \pm 21.87$ & $136.00 \pm 19.51$ & $133.69 \pm 23.29^{\mathrm{a})}$ & $138.33 \pm 20.20^{b)}$ & $3.31 \pm 3.88$ & $2.33 \pm 3.32$ & 0.556 \\
\hline K-ABC & $68.60 \pm 19.41$ & $66.00 \pm 31.11$ & $73.20 \pm 21.48^{\mathrm{b})}$ & $70.00 \pm 36.77$ & $4.60 \pm 2.88$ & $4.00 \pm 5.66$ & 1.000 \\
\hline
\end{tabular}

Values are presented as mean \pm standard deviation.

THR, therapeutic horseback riding; ASD, autism spectrum disorder; ID, intellectual disability; REVT, Receptive and Expressive Vocabulary Test; PRES, Preschool Receptive-Expressive Language Scale; BSID-II, Bayley Scales of Infant Development-II; K-ABC, Kaufman Assessment Battery for Children.

${ }^{\mathrm{a})} \mathrm{p}<0.01$ and ${ }^{\mathrm{b})} \mathrm{p}<0.05$ by Wilcoxon signed-rank test, ${ }^{\mathrm{c})}$ Mann-Whitney test.

Table 3. Therapeutic effects of THR in each disease group, autism spectrum disorder, and intellectual disability

\begin{tabular}{|c|c|c|c|c|c|c|c|c|}
\hline \multirow[b]{2}{*}{ Evaluation } & \multicolumn{4}{|c|}{ Autism spectrum disorder } & \multicolumn{4}{|c|}{ Intellectual disability } \\
\hline & $\begin{array}{c}\text { No. of } \\
\text { patients }\end{array}$ & Baseline & 8 weeks & p-value & $\begin{array}{c}\text { No. of } \\
\text { patients }\end{array}$ & Baseline & 8 weeks & p-value \\
\hline \multicolumn{9}{|l|}{ Language } \\
\hline \multicolumn{9}{|l|}{ REVT } \\
\hline Reception & 12 & $16.58 \pm 20.76$ & $19.42 \pm 21.57$ & $0.007^{*}$ & 6 & $19.17 \pm 20.06$ & $21.50 \pm 21.19$ & $0.042 *$ \\
\hline Expression & 12 & $16.25 \pm 21.60$ & $19.50 \pm 26.12$ & $0.027^{*}$ & 6 & $10.33 \pm 19.69$ & $12.67 \pm 24.06$ & 0.180 \\
\hline \multicolumn{9}{|l|}{ PRES } \\
\hline Reception & 7 & $22.43 \pm 14.02$ & $24.86 \pm 14.47$ & $0.027^{*}$ & 5 & $19.80 \pm 13.72$ & $22.00 \pm 14.51$ & 0.066 \\
\hline Expression & 7 & $16.86 \pm 13.58$ & $18.71 \pm 14.49$ & $0.027^{*}$ & 5 & $13.80 \pm 13.81$ & $18.75 \pm 14.22$ & 0.109 \\
\hline \multicolumn{9}{|l|}{ Cognition } \\
\hline $\begin{array}{l}\text { Cognitive domain } \\
\text { of BSID-II }\end{array}$ & 8 & $130.00 \pm 22.10$ & $133.00 \pm 24.34$ & 0.063 & 5 & $131.00 \pm 24.05$ & $134.80 \pm 24.33$ & $0.042^{*}$ \\
\hline $\mathrm{K}-\mathrm{ABC}$ & 4 & $66.50 \pm 21.75$ & $70.75 \pm 23.98$ & 0.066 & 1 & 77.00 & 83.00 & - \\
\hline
\end{tabular}

Values are presented as mean \pm standard deviation.

THR, therapeutic horseback riding; REVT, Receptive and Expressive Vocabulary Test; PRES, Preschool ReceptiveExpressive Language Scale; BSID-II, Bayley Scales of Infant Development-II; K-ABC, Kaufman Assessment Battery for Children.

${ }^{*} \mathrm{p}<0.05$ by Wilcoxon signed-rank test.

participants with ASD, both in terms of reception $(\Delta=2.43$, $\mathrm{p}=0.027)$ and expression $(\Delta=1.86, \mathrm{p}=0.027)$ (Table 3 ). There was no significant improvement in cognitive function after THR among children with ASD. Participants with ASD who did not receive THR did not demonstrate statistically significant improvements in any of these evaluated domains. Among children with ASD, changes in language function demonstrated by subjects who underwent THR were not significantly different from changes demonstrated by controls.

The ID group $\left(\mathrm{n}_{\mathrm{THR}}=6, \mathrm{n}_{\text {Control }}=4\right)$ demonstrated statistically significant improvements in receptive vocabulary 
ability assessed by REVT-R $(\Delta=2.33, \mathrm{p}=0.042)$ and cognitive function assessed by the cognitive domain of BSID II $(\Delta=3.80, \mathrm{p}=0.042)$ after THR (Table 3). However, no significant change was observed among children with ID who did not undergo THR. As with ASD, among participants with ID, changes in language or cognitive function demonstrated by subjects who underwent THR were not significantly different from changes demonstrated by controls.

\section{DISCUSSION}

This case-control study of 29 patients diagnosed with ASD or ID compared a group who participated in an 8-week THR intervention to a control group who continued conventional therapy. Both groups showed improvements in language and cognition following the intervention phase. However, the THR group showed statistically significant improvements in more items than the control group. In between-group comparison, the degree of improvements ( $\triangle$ Post-Pre) was not statistically significantly greater in the THR group.

Results of the current study were consistent with previous studies suggesting that THR might affect language skills of children with ASD [11]. In a randomized controlled study, Gabriels et al. [11] have assessed behavioral and language-related outcomes of THR using Aberrant Behavior Checklist-Community (ABC-C), Social Responsiveness Scale (SRS), Systematic Analysis of Language Transcripts (SALT), and Peabody Picture Vocabulary Test-fourth edition (PPVT-4). Greater improvements were observed in the THR group compared to controls in terms of behavior, social communication, and expressive vocabulary. Additionally, they reported improvements in social cognition evaluated with SRS and rated by caregiver. Although SRS is a commonly used tool for ASD, it might be considered an insufficient indicator of effects of THR on cognition. To the best of our knowledge, this is the first study to show positive effects of THR on cognitive function using objective testing methods, $\mathrm{K}-\mathrm{ABC}$, and the cognitive domain of BSID-II.

To our knowledge, there has been no published study evaluating effects of THR on children with ID. Our results suggest potential positive effects of THR on language and cognitive function among children with ID. Borioni et al. [13] have divided 23 adults with ID into equestrian reha- bilitation (ER) and onotherapy groups. Psychologist assessed their participants using a rehabilitation program developed at their institution (Villa Buon Respiro in Viterbo, Italy), containing autonomy, motor-praxis, neuropsychological, affective-rational, cognitive, and communication subscales. Overall, there were improvements in autonomy and social integration among subjects with ID who underwent horse and donkey therapy. Cognition and communication findings varied depending on the rater. Effects of ER or onotherapy on cognition and communication were inconclusive. Our results showed improvements in receptive vocabulary ability assessed by REVT-R and cognitive function assessed by the cognitive domain of BSID-II. As with children with ASD, among participants with ID, improvements in cognitive and language skills were not significantly different between those who received THR and those who did not.

It is not clearly known how THR affects the psychobehavior of children with ASD. However, there are several hypotheses. As existing literature indicates, animals are crucial in children's social and cognitive development $[29,30]$. Animal-assisted therapy is known to be beneficial for children with developmental disorders. It involves the notion that animals can act as transitional objects. Children can form primary bonds with animals. Such bonds can then be transferred to humans [31-33]. In THR, riding is not only a fun activity for participants. It also involves getting the child out to do an activity that can facilitate their interactions with both the horse and other people [33]. Promotion of interactions might have been a foundation for improvements of pro-social behavior and communication skills [11,12,34]. Moreover, non-verbal communication between the rider and horse (with horse constantly responding to the rider's body language) may play a role [35]. Through horse's responses to the rider's commands, it might be inferred that children could learn how his or her communication affects the horse's behavior [36]. In addition, during THR, riders maintain postural control and balance throughout the riding. These require attention. These experiences of non-verbal communication and attention might serve as a platform for improvements in communication skills and cognition among children with ASD [35,37]. Another hypothesis about the human-equine experience is that the warmth of horse's body and the horse's rhythmic movements during riding can contribute to a relaxing 
environment which has a calming effect on children with ASD [35,36]. This calming effect may reduce irritability and hyperactivity. It could improve their attention and potentiate effects of other rehabilitation methods, resulting in improved language and cognitive function [11,34]. Rhythmic movements of horses can also stimulate the vestibular system. Occupational therapy research has noted that activities stimulating the vestibular system can promote the production of speech sounds $[38,39]$. Furthermore, feedback from the instructor, provided when a child exhibits inappropriate behavior during THR, may modulate the child's perception of and reactions to the surrounding environment and language stimuli. Ryan et al. [40] have demonstrated that the frequency of such behaviors is decreased when THR progresses in their study of adults with ID, along with improved perception of surroundings and instructions. In a similar context, Borioni et al. [13] have proposed that therapeutic techniques involving horses and donkeys can help adults with ID become more aware of their surroundings owing to consistent responses of animals to human subjects' actions. These controlled interactions can facilitate focus among subjects.

Although the number of subjects was small and there were several limitations, our study was meaningful in that it was the first study to investigate effects of THR on children with ASD or ID, especially in relation to language and cognition assessed by objective testing methods. Furthermore, although the involved mechanisms and pathways are currently unclear as future research provides more evidence, THR might be applied as a treatment for children with ASD or ID to help improve their language and cognitive abilities.

Limitations of this preliminary study include its small sample size. Furthermore, it might be necessary to conduct a longer duration of follow-up assessments after THR to determine whether these improvements of language and cognitive function are temporary or sustained. If studies with larger sample sizes and longer periods of follow-up after THR are conducted, effects of THR could be more definitively elucidated. Another major limitation was that this study did not control variables of conventional therapy. Although this work is meaningful as a preliminary study, it is necessary to identify effects of THR on language and cognition through more rigorous, welldesigned studies in the future. Assessment tools used in this study-REVT, PRES, and BSID-II-are commonly used for children with language or cognitive impairment. These tools have been used for objective assessments in the field of rehabilitation medicine. Findings generated from them should be interpreted carefully because they have not been validated to compare baseline and postrehabilitation status of such children. In order to increase the reliability of this study, further validation of these tools is warranted. Additionally, appropriate protocols for children with ASD or ID were not fully validated. Further studies should be conducted to establish the appropriate number and timing of THR sessions as well as the appropriate age to start THR.

In conclusion, THR with conventional therapy in neurodevelopmental disorders specifically ASD and ID was associated with improvements in almost all domains of language and cognitive assessment suggesting that THR with conventional therapy might have positive effects on language and cognitive impairments. However, improvements associated with THR with conventional therapy were not statistically significantly different from improvements observed in subjects received who conventional therapy only. Further well-designed, larger-scale studies with longer follow-up periods are needed to clearly establish whether THR is an effective technique to improve language and cognitive functions of children with ASD and ID.

\section{CONFLICT OF INTEREST}

No potential conflict of interest relevant to this article was reported.

\section{ACKNOWLEDGMENTS}

This study was conducted with financial support from the Korea Racing Authority.

\section{AUTHOR CONTRIBUTION}

Conceptualization: Sung IY. Methodology: Sung IY, Kwon S, Ko EJ, Kim HS. Formal analysis: Sung IY, Kwon S. Funding acquisition: Sung IY. Project administration: IY Sung. Visualization: Kwon S. Writing - original draft: Kwon S. Writing - review and editing: Sung IY. Approval of final manuscript: all authors. 


\section{REFERENCES}

1. Kwon JY, Chang HJ, Yi SH, Lee JY, Shin HY, Kim YH. Effect of hippotherapy on gross motor function in children with cerebral palsy: a randomized controlled trial. J Altern Complement Med 2015;21:15-21.

2. Baik K, Byeun JK, Baek JK. The effects of horseback riding participation on the muscle tone and range of motion for children with spastic cerebral palsy. J Exerc Rehabil 2014;10:265-70.

3. McGibbon NH, Andrade CK, Widener G, Cintas HL. Effect of an equine-movement therapy program on gait, energy expenditure, and motor function in children with spastic cerebral palsy: a pilot study. Dev Med Child Neurol 1998;40:754-62.

4. McGee MC, Reese NB. Immediate effects of a hippotherapy session on gait parameters in children with spastic cerebral palsy. Pediatr Phys Ther 2009;21:2128.

5. Lechner HE, Kakebeeke TH, Hegemann D, Baumberger $\mathrm{M}$. The effect of hippotherapy on spasticity and on mental well-being of persons with spinal cord injury. Arch Phys Med Rehabil 2007;88:1241-8.

6. Kim H, Her JG, Ko J. Effect of horseback riding simulation machine training on trunk balance and gait of chronic stroke patients. J Phys Ther Sci 2014;26:29-32.

7. Lee DK, Kim EK. The influence of horseback riding training on the physical function and psychological problems of stroke patients. J Phys Ther Sci 2015;27:2739-41.

8. Bronson C, Brewerton K, Ong J, Palanca C, Sullivan SJ. Does hippotherapy improve balance in persons with multiple sclerosis: a systematic review. Eur J Phys Rehabil Med 2010;46:347-53.

9. Cuypers K, De Ridder K, Strandheim A. The effect of therapeutic horseback riding on 5 children with attention deficit hyperactivity disorder: a pilot study. J Altern Complement Med 2011;17:901-8.

10. Johnson RA, Albright DL, Marzolf JR, Bibbo JL, Yaglom HD, Crowder SM, et al. Effects of therapeutic horseback riding on post-traumatic stress disorder in military veterans. Mil Med Res 2018;5:3.

11. Gabriels RL, Pan Z, Dechant B, Agnew JA, Brim N, Mesibov G. Randomized controlled trial of therapeutic horseback riding in children and adolescents with autism spectrum disorder. J Am Acad Child Adolesc
Psychiatry 2015;54:541-9.

12. Bass MM, Duchowny CA, Llabre MM. The effect of therapeutic horseback riding on social functioning in children with autism. J Autism Dev Disord 2009; 39:1261-7.

13. Borioni N, Marinaro P, Celestini S, Del Sole F, Magro R, Zoppi D, et al. Effect of equestrian therapy and onotherapy in physical and psycho-social performances of adults with intellectual disability: a preliminary study of evaluation tools based on the ICF classification. Disabil Rehabil 2012;34:279-87.

14. American Psychiatric Association. Diagnostic and statistical manual of mental disorders (DSM-5). Arlington, VA: American Psychiatric Publishing; 2013.

15. Gabriels RL, Agnew JA, Miller LJ, Gralla J, Pan Z, Goldson E, et al. Is there a relationship between restricted, repetitive, stereotyped behaviors and interests and abnormal sensory response in children with autism spectrum disorders? Res Autism Spectr Disord 2008;2:660-70.

16. Daily DK, Ardinger HH, Holmes GE. Identification and evaluation of mental retardation. Am Fam Physician 2000;61:1059-67.

17. Centers for Disease Control and Prevention. Data \& Statistics on autism spectrum disorder [Internet]. Atlanta, GA: Centers for Disease Control and Prevention; c2018 [cited 2019 May 15]. Available from: http:// www.cdc.gov/ncbddd/autism/data.html.

18. Long C, Gurka MJ, Blackman J. Cognitive skills of young children with and without autism spectrum disorder using the BSID-III. Autism Res Treat 2011; 2011:759289.

19. Autism and Developmental Disabilities Monitoring Network Surveillance Year 2008 Principal Investigators; Centers for Disease Control and Prevention. Prevalence of autism spectrum disorders--Autism and Developmental Disabilities Monitoring Network, 14 sites, United States, 2008. MMWR Surveill Summ 2012;61:1-19.

20. Horlin C, Falkmer M, Parsons R, Albrecht MA, Falkmer T. The cost of autism spectrum disorders. PLoS One 2014;9:e106552.

21. Ervin DA, Merrick J. Intellectual and developmental disability: healthcare financing. Front Public Health 2014;2:160.

22. Kim YT, Hong GH, Kim KH. (2009). Content and re- 
liability analyses of the receptive and expressive vocabulary test (REVT). Korean J Commun Disord 2009; 14:34-45.

23. Choi SW, Seo HS, Lee HJ, Lee KW, Kim CA, Son BH. Assessment of children with language developmental delay: Korean Infant and Child Development Test (KICDT) and Preschool Receptive-Expressive Language Scale (PRES), Sequenced Language Scale for Infant (SELSI). J Korean Child Neurol Soc 2015;23:51-6.

24. Clark B. Outcomes of dog-assisted therapy for children and adolescents with autism spectrum disorder [master's thesis]. Sydney: The University of Sydney; 2018.

25. Pivalizza P. Intellectual disability in children: management, outcomes, and prevention [Internet]. Waltham, MA; UpToDate; 2018 [cited 2019 May 15]. Available from: https://www.uptodate.com/contents/intellectual-disability-in-children-management-outcomesand-prevention.

26. McKown DM. A comparison study: Kaufman Assessment Battery for Children, second edition (KABC-II) and Wechsler Intelligence Scale for Children, fourth edition (WISC-IV) with referred students [master's thesis]. Huntington, WV: Marshall University; 2010.

27. Park HW, Cho BH. Korean-Bayley Scales of Infant Development: interpretation manual. 2nd ed. Seoul: Kidspop Publishing Co.; 2006.

28. Bayley N. Bayley Scales of Infant Development: manual. 2nd ed. San Antonio, TX: Psychological Corporation; 1993.

29. Triebenbacher SL. The companion animal within the family system: the manner in which animals enhance life within the home. In: Fine AH, editor. Handbook on animal-assisted therapy. 2nd ed. San Diego, CA: Academic Press; 2006. p. 357-74

30. Melson GF. Companion animals and the development of children: Implications of the biophilia hypothesis. In: Fine AH, editor. Handbook on animal-assisted therapy. 2nd ed. San Diego, CA: Academic Press; 2006. p. 375-83.

31. Katcher AH. The future of education and research on the animal-human bond and animal-assisted therapy. Part B: Animal-assisted therapy and the study of hu- man-animal relationships: discipline or bondage? context or transitional object? In: Fine AH, editor. Handbook on animal-assisted therapy. 2nd ed. San Diego, CA: Academic Press; 2006. p. 461-73.

32. Katcher A, Wilkins GG. Animal-assisted therapy in the treatment of disruptive behavior disorders in children. In: Lundberg A, editor. The environment and mental health: a guide for clinicians. Mahwah, NJ: Lawrence Erlbaum Associates; 1998. p. 193-204.

33. Martin F, Farnum J. Animal-assisted therapy for children with pervasive developmental disorders. West J Nurs Res 2002;24:657-70.

34. Ward SC, Whalon K, Rusnak K, Wendell K, Paschall $\mathrm{N}$. The association between therapeutic horseback riding and the social communication and sensory reactions of children with autism. J Autism Dev Disord 2013;43:2190-8.

35. Stoner J. Efficacy of hippotherapy as a treatment strategy for children with autism. In: Engel BT, MacKinnon JR, editors. Enhancing human occupation through hippotherapy. Bethesda, MD: AOTA Press; 2007. p. 103-10.

36. Gabriels RL, Agnew JA, Holt KD, Shoffner A, Zhaoxing $\mathrm{P}$, Ruzzano S, et al. Pilot study measuring the effects of therapeutic horseback riding on school-age children and adolescents with autism spectrum disorders. Res Autism Spectr Disord 2012;6:578-88.

37. Fougnie D. The relationship between attention and working memory. In: Johansen NB, editor. New research on short-term memory. New York: Nova Biomedical Books; 2008. p. 1-45.

38. Bhatara V, Clark DL, Arnold LE, Gunsett R, Smeltzer DJ. Hyperkinesis treated by vestibular stimulation: an exploratory study. Biol Psychiatry 1981;16:269-79.

39. Ray TC, King LJ, Grandin T. The effectiveness of selfinitiated vestibular stimulation in producing speech sounds in an autistic child. Occup Ther J Res (OTJR) 1988;8(3):186-90.

40. Ryan G, Brady S, Holloway J, Lydon H. Increasing appropriate conversation skills using a behavioral skills training package for adults with intellectual disability and autism spectrum disorder. J Intellect Disabil 2017 Jan 1 [Epub]. http://doi.org/10.1177/1744629517750744. 